\title{
A new phosphonate pendant-armed cross-bridged tetraamine chelator accelerates copper(II) binding for radiopharmaceutical applications $\uparrow$
}

\author{
Dannon J. Stigers, ${ }^{a}$ Riccardo Ferdani, ${ }^{b}$ Gary R. Weisman, ${ }^{a}$ Edward H. Wong, ${ }^{* a}$ Carolyn J. Anderson, ${ }^{* b}$ \\ James A. Golen, ${ }^{c}$ Curtis Moore $^{d}$ and Arnold L. Rheingold ${ }^{d}$
}

Received 8th October 2009, Accepted 26th November 2009

First published as an Advance Article on the web 15th December 2009

DOI: 10.1039/b920871b

A phosphonate pendant-armed cross-bridged cyclam chelator has been synthesized, complexed to $\mathrm{Cu}$ (II), radiolabeled with ${ }^{64} \mathrm{Cu}$ under mild conditions, and its biodistribution studied.

The family of ethylene cross-bridged cyclam macrobicycles has received increasing attention as chelators in radiopharmaceutical research. ${ }^{1,2}$ An especially promising ligand for radio-copper binding is the dicarboxymethyl pendant-armed ligand 1 (CB-TE2A, Fig. 1) which imparts remarkable kinetic inertness to its $\mathrm{Cu}$ (II) complex resulting in superior in vivo behavior of its ${ }^{64} \mathrm{Cu}$-labeled bioconjugates. ${ }^{3,4}$ However, its sluggish radiolabeling kinetics has necessitated the use of relatively harsh protocols $\left(e . g .85^{\circ} \mathrm{C}, \mathrm{pH} 8\right.$, $1 \mathrm{~h}$ ). While still practicable for bioconjugates of some biological targeting vectors, ${ }^{5}$ these severe labeling conditions have precluded the use of more sensitive peptides or biomolecules.
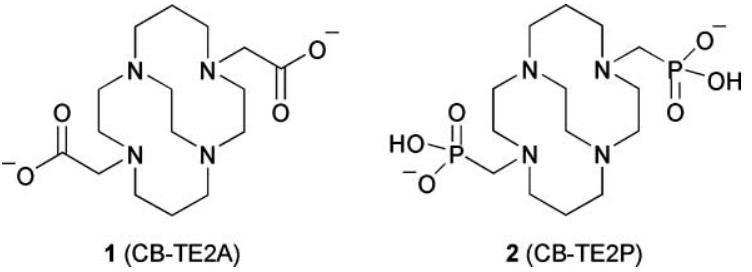

Fig. 1 Structures of ligands 1 (CB-TE2A) and 2 (CB-TE2P).

Phosphonate pendant-armed cyclen and cyclam derivatives have been reported to have accelerated metal-binding kinetics relative to their carboxylate-armed analogues while retaining high thermodynamic stabilities of their complexes. ${ }^{6-10}$ We report here the synthesis and characterization of a di-methanephosphonate pendant-armed cross-bridged cyclam 2 (CB-TE2P), its $\mathrm{Cu}$ (II) complex as well as its ${ }^{64} \mathrm{Cu}$ radiolabeling and in vivo biodistribution studies.

${ }^{a}$ Department of Chemistry, University of New Hampshire, Durham, New Hampshire,03824,USA.E-mail: gary.weisman@unh.edu,ehw@cisunix. unh.edu

${ }^{b}$ Mallinckrodt Institute of Radiology, Washington University School of Medicine, St. Louis, Missouri,63110,USA.E-mail: andersoncj@wustl.edu 'Department of Chemistry and Biochemistry, University of California, San Diego, La Jolla, California, 92093, USA

${ }^{d D e p a r t m e n t ~ o f ~ C h e m i s t r y ~ a n d ~ B i o c h e m i s t r y, ~ U n i v e r s i t y ~ o f ~ M a s s a c h u s e t t s, ~}$ Dartmouth, North Dartmouth, Massachusetts, 02747, USA

$\dagger$ Electronic supplementary information (ESI) available: Synthesis, characterization, and NMR spectra of precursor $\mathbf{4}$ and ligand 2; synthesis and characterization of the $\mathrm{Cu}(\mathrm{II})$ complex of 2 ; X-ray crystallographic data for $\mathrm{H}_{2} 2 \cdot \mathrm{HCl} \cdot 4 \mathrm{H}_{2} \mathrm{O}$ and $\mathrm{Cu}-2$; and biodistribution data of ${ }^{64} \mathrm{Cu}-2$ in male Lewis rats. CCDC reference numbers $750366 \& 750367$. For ESI and crystallographic data in CIF format see DOI: 10.1039/b920871b
Ligand 2 was synthesized as shown in Scheme 1. Parent crossbridged cyclam 3 was first converted to bis-diethylphosphonate 4 by a variant of the Kabachnik-Fields three-component reaction ${ }^{11,12}$ and this synthetic intermediate was then hydrolyzed to the title ligand. Thus, reaction of $\mathbf{3}$ with triethylphosphite and paraformaldehyde in anhydrous THF under nitrogen at room temperature for 4 days gave pure 4 in 94\% yield after extractive workup. 4 was hydrolyzed in $6 \mathrm{~N} \mathrm{HCl}$ under reflux for $24 \mathrm{~h}$ to give $\mathrm{H}_{2} 2$ in $64 \%$ yield as a hydrochloride after purification by ion-exchange chromatography.

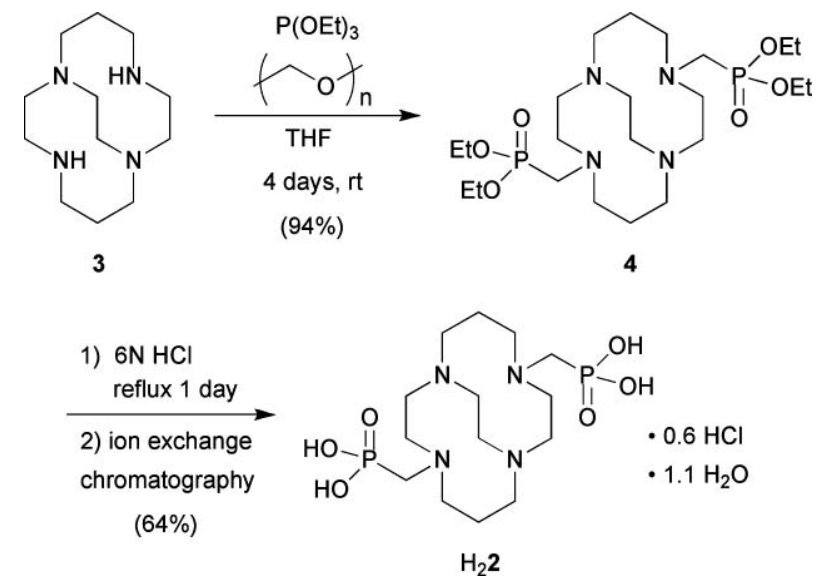

Scheme 1 Synthesis of ligand 2.

Diffusion of acetone into an aqueous solution gave crystals of $\mathrm{H}_{2}$ 2 $\cdot \mathrm{HCl} \cdot 4 \mathrm{H}_{2} \mathrm{O}$ suitable for X-ray crystallography. The structure (Fig. 2) shows the ligand to be di-inside-protonated and the two phosphonate arms to be intramolecularly $\mathrm{O}-\mathrm{H} \cdots \mathrm{O}$ hydrogen bonded. The ligand adopts a [2233]/[2233] conformation rather than the $[2323] /[2323]$ conformation, ${ }^{13,14}$ perhaps in order to facilitate the appropriate arm-arm distance for the intramolecular H-bond.

The $\mathrm{Cu}$ (II) complex of $\mathbf{2}$ was first prepared from $\mathrm{CuCl}_{2}$ and the ligand in refluxing methanol with the $\mathrm{pH}$ adjusted to 8 using aqueous $\mathrm{NaOH}$. Subsequently, it was found that complexation in methanol was actually complete in less than $5 \mathrm{~min}$ at ambient temperature. The blue complex $\left(\lambda_{\max }(\mathrm{MeOH}) / \mathrm{nm} 639\right.$ $\left.\left(\varepsilon / \mathrm{dm}^{3} \mathrm{~mol}^{-1} \mathrm{~cm}^{-1} 35\right)\right)$ was studied by cyclic voltammetry in $0.1 \mathrm{M}$ aq. $\mathrm{NaOAc}$. It exhibited a quasi-reversible reduction at $-0.96 \mathrm{~V}$ (Ag/AgCl), typical of $\mathrm{Cu}(\mathrm{II})$ cross-bridged cyclam complexes. ${ }^{15}$ Its acid inertness was assayed under pseudo first-order conditions in $5 \mathrm{M} \mathrm{HCl}$ at $90{ }^{\circ} \mathrm{C}$ and found to have a half life of 3.8(1) h. While this is considerably shorter than the $154 \mathrm{~h}$ previously reported for 


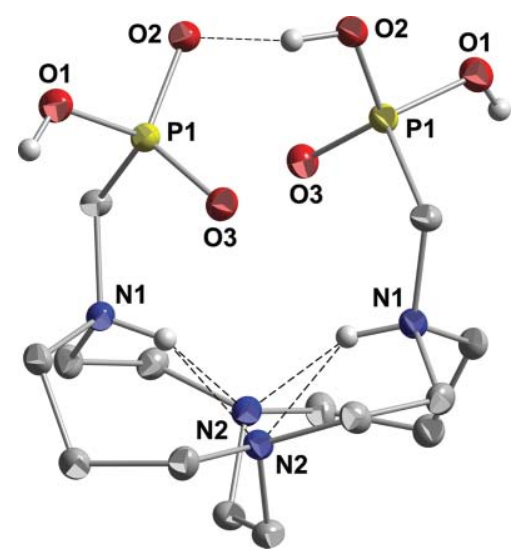

Fig. 2 X-ray structure of $\mathrm{H}_{2} \cdot \mathbf{2} \cdot \mathrm{HCl} \cdot 4 \mathrm{H}_{2} \mathrm{O}(50 \%$ thermal ellipsoids for all non-hydrogen atoms). Intramolecular hydrogen bonds are shown as dashed lines. One of the two half-occupancy symmetry-related hydrogens on $\mathrm{O} 2$ has been removed for clarity and so that the H-bond can be shown.

$\mathrm{Cu}-\mathbf{1}$, it is significantly more inert than Cu-DOTA and Cu-TETA, both of which were completely decomplexed within minutes. ${ }^{15}$

The X-ray crystal structure of $\mathrm{Cu}-2 \$$ is shown in Fig. 3. Full envelopment of the cation within the ligand's $\mathrm{N}_{4} \mathrm{O}_{2}$ donor set can be seen in its distorted octahedral coordination mode. Elongated bond lengths of $2.20 \AA$ for $\mathrm{N}(4)-\mathrm{Cu}(1)$ and $2.45 \AA$ for $\mathrm{Cu}(1)-\mathrm{O}(6)$ designate the Jahn-Teller distortion axis. An $\mathrm{N}(1)-\mathrm{Cu}(1)-\mathrm{N}(3)$ bond angle of $174.8^{\circ}$ confirms a good fit of the cation inside the chelator cavity which can be compared to the $177.5^{\circ}$ reported for $\mathrm{Cu}-1 .{ }^{16}$ Again the ligand adopts the [2233]/[2233] conformation rather than the distorted diamondlattice [2323]/[2323] conformation more commonly seen in $\mathrm{Cu}(\mathrm{II})$ complexes of cross-bridged cyclams, including $\mathrm{Cu}-1 .{ }^{16}$

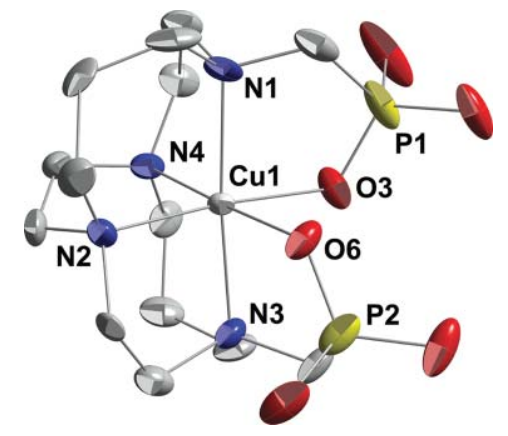

Fig. 3 X-ray structure of $\mathrm{Cu}-2$ (50\% thermal ellipsoids for all non-hydrogen atoms. Only one of two independent complexes is shown. Both exhibit distorted octahedral coordination at $\mathrm{Cu}$ and have the same basic ligand conformation. Hydrogens, sodium and chloride ions, and solvent molecules have been removed for clarity.)

Even though 2 showed rapid $\mathrm{Cu}^{2+}$ complexation in methanol and ethanol, the radiolabeling experiments with ${ }^{64} \mathrm{Cu}$ were performed in water or aqueous buffers since organic solvents are not well tolerated by animals and therefore less convenient for in vivo experiments. No-carrier-added ${ }^{64} \mathrm{Cu}-\mathbf{2}$ was prepared in water by addition of a solution of ${ }^{64} \mathrm{CuCl}_{2}$ in $0.1 \mathrm{M} \mathrm{HCl}$ to a $2-5 \mathrm{mM}$ solution of the ligand in water. We found that radio-TLC was not adequate for determining labeling purity as it only differentiated between free and chelated ${ }^{64} \mathrm{Cu}$. By contrast, radio-HPLC was able to resolve whether more than one product formed. Thus at room temperature, "exo-complexes" (vide infra) were observed, while $100 \%$ formation of the fully-engulfed complex was obtained at higher temperatures $\left(>90^{\circ} \mathrm{C}\right)$ as confirmed by LC-MS and radioLC-MS compared to an authentic sample. Under carrier-added conditions (molar ratio of ligand $/ \mathrm{Cu}^{2+}=100: 35$ ) ${ }^{64} \mathrm{Cu}-2$ formed in a $100 \%$ yield even at room temperature.

Under no-carrier-added conditions (molar ratio of ligand/ $\left.\mathrm{Cu}^{2+}>10^{5}: 1\right)$ radioactive peaks were observed by LC-MS at lower retention times than that of ${ }^{64} \mathrm{Cu}-\mathbf{2}$. This is attributed to the slower kinetics of complex formation with extremely low concentrations of $\mathrm{Cu}^{2+}$ (nM to $\left.\mathrm{pM}\right)$. One hypothesis is that the formation of "exo" or "out of cleft" complexes occurs initially, rather than the fully encapsulated form that is shown in the crystal structure. At this stage the $\mathrm{Cu}^{2+}$ is only bound to one or more of the pendant arms, and its coordination sphere is likely to contain water molecules, while some of the nitrogen atoms in the macrocycle remain protonated. The conversion to the thermodynamically stable final complex is a slower process that can be accelerated either by increasing copper concentration (carrier-added conditions) or by heating.

Another possibility is the presence of trace level impurities $(<1 \%)$ that bind ${ }^{64} \mathrm{Cu}^{2+}$ more rapidly than 2 . Adding cold copper saturates the impurities and the thermodynamically favored ${ }^{64} \mathrm{Cu}$ 2 preferentially forms. Increasing the temperature also favors the formation of the desired complex due to its superior thermodynamic stability. A similar hypothesis was formulated in 2005 by Boswell et al. ${ }^{17}$ for the labeling of compound $\mathbf{1}$.

In order to gain an insight into the pharmacokinetics of ${ }^{64} \mathrm{Cu}-\mathbf{2}$, a biodistribution study was performed on 26-day-old Lewis male rats. ${ }^{64} \mathrm{Cu}-2(50 \mu \mathrm{Ci}(\sim 1 \mu \mathrm{Ci} / \mu \mathrm{g})$ in $150 \mu \mathrm{L}$ of saline $)$ was injected through the tail vein, and the animals were sacrificed at 1, 2, 4 and $24 \mathrm{~h}$ after injection. The organs were harvested and their activity measured with a $\gamma$ counter.

As shown in Fig. 4, the radiolabeled compound clears rapidly from the blood (from $0.15 \% \mathrm{ID} / \mathrm{g}$ at $1 \mathrm{~h}$ to $0.002 \mathrm{ID} / \mathrm{g}$ at $24 \mathrm{~h}$ ) and has only minor residual uptake in organs such as liver, spleen, lung, heart and marrow (not higher than $0.03 \% \mathrm{ID} / \mathrm{g}$ at $24 \mathrm{~h}$ ). Rapid clearance of ${ }^{64} \mathrm{Cu}-2$ from the liver is indicative of its high in vivo stability, as it is known that dissociated ${ }^{64} \mathrm{Cu}$ is rapidly coordinated by liver proteins such as SOD, ceruloplasmin and metallothionein. ${ }^{18}$

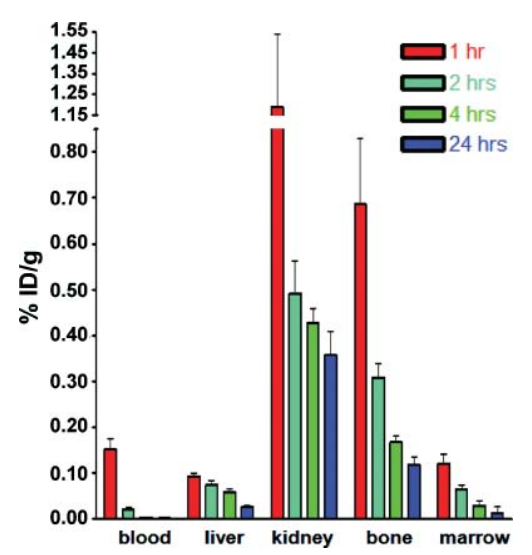

Fig. 4 Biodistribution of ${ }^{64} \mathrm{Cu}-2$ in male Lewis rats at 1, 2, 4, and $24 \mathrm{~h}$ post-injection (in \% Injected Dose/gram). 
The biodistribution data demonstrate that ${ }^{64} \mathrm{Cu}-2$ is rapidly excreted through the kidney, where there is $0.36 \% \mathrm{ID} / \mathrm{g}$ after $24 \mathrm{~h}$. Not surprisingly, at earlier time points a significant percentage of radioactivity was observed in the bone, most likely due to the affinity of the methanephosphonic pendant arms for the hydroxyapatite in the bone; however, this activity is cleared severalfold by $24 \mathrm{~h}$ post-injection. Similar results were obtained for methanephosphonic derivatives of cyclen. ${ }^{9}$

Unlike the recently-reported 4,11-dimethyl-cyclam-1,8bis(methylphosphonic acid), ${ }^{10}$ chelator 2 forms a sufficiently inert $\mathrm{Cu}$ (II) complex for radiopharmaceutical applications. Syntheses and bioconjugation of unsymmetrically functionalized monophosphonate cross-bridged cyclam are under active investigation in our laboratories and will be reported in due course.

\section{Acknowledgements}

This work was supported by National Institutes of Health (U.S.A) grant CA093375.

\section{Notes and references}

† Crystal data for 2: $\mathrm{C}_{14} \mathrm{H}_{41} \mathrm{ClN}_{4} \mathrm{O}_{10} \mathrm{P}_{2}$, monoclinic, $C 2, a=11.5219(16)$, $b=11.7468(16), c=9.6554(13) \AA, \beta=115.254(3)^{\circ}, V=1181.9(3) \AA^{3}$, $Z=2, T=100(2) \mathrm{K}$. 6044 reflections collected, 2590 unique, Bruker D8 diffractometer $(\mathrm{Mo}-\mathrm{K} \alpha) \cdot R_{1}=3.37 \%, \mathrm{w} R_{2}=8.35 \%(I>2 \sigma I)$. Refined as a racemic $(68 / 32)$ twin.

Crystal data for Cu-2: $\mathrm{C}_{14} \mathrm{H}_{34} \mathrm{Cl}_{0.5} \mathrm{CuNa}_{0.5} \mathrm{~N}_{4} \mathrm{O}_{9.5} \mathrm{P}_{2}$, triclinic, $P \overline{1}, a=$ 9.5428(5), $b=15.5173(7), c=16.9240(10) \AA, \alpha=80.039(4), \beta=$ 81.081(4), $\gamma=89.874(3)^{\circ}, V=2437.7(2) \AA^{3}, Z=4, T=100(2) \mathrm{K} .16637$ reflections collected, 6611 unique, Bruker Kappa diffractometer $(\mathrm{Cu}-\mathrm{K} \alpha)$. $R_{1}=7.41 \%$, w $R_{2}=19.68 \%(I>2 \sigma I)$. Hydrogen atoms on solvent water molecules were ignored in refinement, but included in computations and formula.

1 M. Shokeen and C. J. Anderson, Acc. Chem. Res., 2009, 42, 832-841.

2 T. J. Wadas, E. H. Wong, G. R. Weisman and C. J. Anderson, Curr. Pharm. Des., 2007, 13, 3-16.

3 J. E. Sprague, Y. Peng, X. Sun, G. Weisman, E. Wong, S. Achilefu and C. Anderson, Clin. Cancer Res., 2004, 10, 8674-8682.

4 L. Wei, C. Butcher, Y. Miao, F. Gallazzi, T. P. Quinn, M. J. Welch and J. S. Lewis, J. Nucl. Med., 2007, 48, 64-72.

5 L. Wei, Y. Ye, T. Wadas, J. S. Lewis, M. J. Welch, S. Achilefu and C. J. Anderson, Nucl. Med. Biol., 2009, 36, 277-285.

6 S. Füzerová, J. Kotek, I. Císařová, P. Hermann, K. Binnemans and I. Lukeš, Dalton Trans., 2005, 2908-2915.

7 J. Kotek, P. Lubal, P. Hermann, I. Cisarova, I. Lukes, T. Godula, I. Svobodova, P. Taborsky and J. Havel, Chem.-Eur. J., 2003, 9, 233-248.

8 I. Lukeš, J. Kotek, P. Vojtíšek and P. Hermann, Coord. Chem. Rev, 2001, 216-217, 287-312.

9 X. Sun, M. Wuest, Z. Kovacs, A. D. Sherry, R. Motekaitis, Z. Wang, A. E. Martell, M. J. Welch and C. J. Anderson, JBIC, J. Biol. Inorg. Chem., 2003, 8, 217-225.

10 I. Svobodová, J. Havlícková, J. Plutnar, P. Lubal, J. Kotek and P. Hermann, Eur. J. Inorg. Chem., 2009, 3577-3592.

11 P. Kafarski and J. Zon, in Aminophosphonic Aminophosphinic Acids, ed. V. P. Kukhar and H. R. Hudson, John Wiley \& Sons, Ltd., Chichester, 2000, pp. 33-74.

12 M. Syamala, Org. Prep. Proced. Int., 2005, 37, 103-171.

13 J. Dale, Acta Chem. Scand., 1973, 27, 1115-1129.

14 J. Dale, in Topics in Stereochemistry, ed. N. L. Allinger and E. L. Eliel, John Wiley \& Sons, New York, 1976, vol. 9, pp. 199-270.

15 K. S. Woodin, K. J. Heroux, C. A. Boswell, E. H. Wong, G. R. Weisman, W. Niu, S. A. Tomellini, C. J. Anderson, L. N. Zakharov and A. L. Rheingold, Eur. J. Inorg. Chem., 2005, 4829-4833.

16 E. H. Wong, G. R. Weisman, D. C. Hill, D. P. Reed, M. E. Rogers, J. S. Condon, M. A. Fagan, J. C. Calabrese, K.-C. Lam, I. A. Guzei and A. L. Rheingold, J. Am. Chem. Soc., 2000, 122, 10561-10572.

17 C. A. Boswell, P. McQuade, G. Weisman, E. Wong and C. Anderson, Nucl. Med. Biol., 2005, 32, 29-38.

18 C. Boswell, X. Sun, W. Niu, G. Weisman, E. Wong, A. Rheingold and C. Anderson, J. Med. Chem., 2004, 47, 1465-1474. 